\title{
Perspectivas sobre protocolos de biossegurança para realização de aulas práticas no serviço de saúde: o que pode ser efetivamente aplicado ao contexto de Jataí-GO
}

\author{
Nathalia Bandeira de Almeida ${ }^{1}$ \\ Beatriz Pereira Vilela ${ }^{2}$ \\ Carlos Henrique Gusmão Sobrinho ${ }^{3}$ \\ Marcela Costa de Almeida Silva ${ }^{4}$ \\ Sara Alves França ${ }^{5}$ \\ Mariana Bodini Angeloni ${ }^{6}$
}

\section{RESUMO:}

As medidas de distanciamento social, em virtude da pandemia do COVID-19, refletiram na dinâmica dos estabelecimentos de ensino em todo o mundo, dentre elas o fechamento de universidades. Nessa mesma ótica, o Brasil foi de encontro aos outros países, acarretando principalmente, ausência de aulas práticas dos cursos da área da saúde. Com isso, urge ressaltar que as universidades se organizem por meio dos protocolos de biossegurança para que a abertura e o retorno de aulas práticas se dêem de forma segura de acordo com a epidemiologia de cada região. Logo, esse artigo aborda a problemática inserida na graduação dos cursos da saúde na Universidade Federal de Jataí e propõe protocolos de biossegurança que podem ser implementados de acordo com a epidemiologia do município de Jataí-GO, o qual preza sempre, pela saúde e segurança dos profissionais e estudantes da universidade a fim de garantir a segurança da comunidade acadêmica e a qualidade educacional.

Palavras-chaves: COVID-19. Prática em saúde. Epidemiologia.

\section{Perspectives on biosafety protocols for conducting practical classes in the health service: what can be effectively applied to the context of Jataí-GO}

\begin{abstract}
:
Measures of social distance corresponding to a pandemic of the new coronavirus have had harmful consequences worldwide, including the closure of universities. In this light, Brazil went against other countries, mainly resulting in the absence of practical classes in courses in the area of health. With this, it is urgent to emphasize that universities organize themselves through biosafety protocols so that the opening and return of practical classes takes place in a safe manner, according to the epidemiology of each region. Therefore, this article addresses the issue inserted in the graduation of health courses at the Federal University of Jataí and proposes biosafety protocols that can be implemented according to the epidemiology of the municipality of Jataí-GO which always values the health and safety of professionals and university students to ensure the safety of the academic community and educational quality.
\end{abstract}

Keyword: COVID-19. Health practice. Epidemiology.

\footnotetext{
${ }^{1}$ Acadêmica de Medicina na Universidade Federal de Jataí (UFJ). E-mail: nathaliaalmeida@ discente.ufj.edu.br

2 Acadêmica de Medicina na Universidade Federal de Jataí (UFJ). E-mail: beatrizp.vilela@ discente.ufj.edu.br

${ }^{3}$ Acadêmico de Medicina na Universidade Federal de Jataí (UFJ). E-mail: carlosgusmao@discente.ufj.edu.br

${ }^{4}$ Acadêmica de Medicina na Universidade Federal de Jataí (UFJ). E-mail: marcelacosta@ discente.ufj.edu.br

${ }^{5}$ Acadêmica de Medicina na Universidade Federal de Jataí (UFJ). E-mail: saraalves@ discente.ufj.edu.br

${ }^{6}$ Docente do curso de Medicina na Universidade Federal de Jataí (UFJ), doutora em Imunologia e Parasitologia

Aplicadas. E-mail: marianabodini@ufj.edu.br
} 


\section{INTRODUÇÃO}

SARS-CoV-2 é um novo vírus de RNA de fita simples pertencente à família Coronaviridae. O surto da doença infecciosa causada pelo SARS -CoV-2 em 2019 (COVID19) se iniciou na cidade de Wuhan, China, o qual evoluiu rapidamente em uma crise de saúde pública e se espalhou exponencialmente para outras partes do mundo. (ATHER et al., 2020; SILVA; JARDIM; SIQUEIRA, 2020). Em janeiro de 2020, o surto da COVID-19 foi declarado em escala internacional como emergência de saúde pública, tornando-se um dos maiores desafios para a saúde mundial (DA SILVA MOURA et al., 2020).

Diante disso, a maioria dos países fechou temporariamente instituições educacionais na tentativa de conter a disseminação do vírus da COVID-19 (UNESCO, 2020a). Segundo dados da Organização das Nações Unidas para a Educação, Ciência e Cultura - Unesco (2020a), uma das medidas para conter a propagação do vírus foi o fechamento de escolas, universidades, instituições de educação em geral em mais de 190 países por mais de dois meses, afetando cerca de $90 \%$ da população estudantil do mundo como uma medida protetiva para conter a propagação do vírus.

No Brasil foi declarada Emergência em saúde Pública de Importância Nacional (ESPIN) em decorrência da COVID-19 por meio da Portaria n. 188, de 3 de fevereiro de 2020, publicada no DOU de 4 de fevereiro de 2020 (BRASIL, 2020). Essa declaração possibilitou que os estados federativos em conjunto com o Sistema Único de Saúde (SUS) adotassem com urgência, medidas de controle de danos atrelados à pandemia por meio da contenção de riscos e prevenção que agravasse a saúde pública (DINIZ, 2020). Com o agravamento da situação, após o início da pandemia houve o fechamento de instituições educacionais, sendo estas substituídas por ensino remoto como meio de medidas profiláticas para impedir a propagação do vírus.

Um documento elaborado pela OMS (2020a) destaca que é necessário avaliar o conhecimento sobre transmissão da COVID-19 nas instituições de ensino, e analisar a situação epidemiológica em cada local específico, além da capacidade das escolas e universidades de manter medidas de prevenção e controle da doença (SOARES, 2020).

Logo, é evidente que, estratégia de ensino para se adaptar à nova realidade que é inserida na sociedade é crucial para conter os efeitos maléficos da pandemia. Porém, é indiscutível que a ausência de aulas práticas do curso de medicina compromete a formação destes estudantes, haja visto que o contato com o paciente é essencial na formação médica de qualidade. 
O objetivo deste estudo foi estabelecer protocolos com medidas de biossegurança para o retorno das aulas práticas de medicina aplicadas à situação epidemiológica no município de Jataí-GO.

\section{DESENVOLVIMENTO}

\subsection{ANÁliSE EPIDEMIOLÓGICA DE JATAí E OS MARCOS LEGAIS CRUCIAIS PARA O PLANO DE RETOMADA DE ATIVIDADES PRESENCIAIS.}

Para a construção de planos de retorno às atividades de ensino de forma presencial, necessita-se de marcos legais que deem respaldo e uma análise epidemiológica local e que possibilite um retorno de forma segura. Dentre os marcos legais a serem utilizados encontra-se a Lei $n^{\circ}$ 9.394, de 1996, de diretrizes e bases da educação nacional, a Resolução CEE/CP N. 14, de 07 de agosto de 2020, que permite que Instituições de ensino superior tenham aulas presenciais, a PORTARIA N 1.030, DE $1^{\circ}$ DE DEZEMBRO DE 2020, que dispõe sobre o retorno às aulas presenciais e sobre caráter excepcional de utilização de recursos educacionais digitais para integralização da carga horária das atividades pedagógicas enquanto durar a situação de pandemia do novo coronavírus ,a Portaria MEC n 572, de 2020, que institui o Protocolo de Biossegurança para Retorno das Atividades nas Instituições Federais de Ensino e dá outras providências, e eventual futuro parecer de órgãos estaduais ou federais com orientações para o retorno às atividades presenciais. (MINISTÉRIO DA EDUCAÇÃO, 2020)

Em relação à análise epidemiológica do município de Jataí-GO, segundo a Secretaria de Saúde de Jataí, desde o início da pandemia até o dia 06 de abril de 2021, foram notificados, no município, 19.845 casos suspeitos de COVID-19. Dentre esses, 9.258 foram confirmados como COVID-19, 1070 foram descartados, 5.318 ainda estavam em investigação, sendo que destes, 09 foram a óbito. Ainda, 3.998 casos foram encerrados como Síndrome Gripal Não Especificada e outros 201 casos foram encerrados como Síndrome Respiratória Aguda Grave Não Especificada. Dos pacientes confirmados, no dia 06 de abril de 2021, 25 estavam em isolamento hospitalar e 1.129 se encontravam em isolamento domiciliar (SECRETARIA MUNICIPAL DE SAÚDE DE JATAÍ, 2021).

No entanto, um número de pacientes, bem menos significativo, evoluiu para óbito, sendo 202 óbitos e 7902 recuperados do número total de confirmados, representando na data 
do dia 06 de abril de 2021 uma taxa de letalidade da COVID-19 em Jataí de 2,18\%. Além disso, tinha-se na data referida uma taxa de ocupação de leitos exclusivos para COVID-19 de: UTI SUS $(88,9 \%)$, enfermaria SUS $(78,4 \%)$, UTI conveniada ao SUS $(100,0 \%)$ e enfermaria privada $(31,6 \%)$, porém do total de internados, 11 residiam em outros municípios, sendo que 08 estavam ocupando leitos de UTI e 03 ocupavam leitos de enfermaria (SECRETARIA MUNICIPAL DE SAÚDE DE JATAÍ, 2021).

Em relação a dados de vacinação no município de Jataí colhidos no dia 01 de abril de 2021, 9369 pessoas já tinham sido vacinadas com a primeira dose, sendo 1934 trabalhadores da saúde; 7391 idosos; 24 agentes funerários/coveiros; 20 pessoas com deficiências. Ademais, 2013 pessoas foram vacinadas com a segunda dose, sendo 1140 trabalhadores da saúde; 871 idosos; 2 agentes funerários/coveiros; 0 pessoas com deficiências. Coloca-se ainda, o adendo de que o quantitativo de doses recebidas pelo município foi de 10.640 que eram destinados à aplicação da primeira $1^{\text {a }}$ dose, e mais 2.590 doses para a aplicação da segunda dose (SECRETARIA MUNICIPAL DE SAÚDE DE JATAÍ, 2021).

\subsection{INSERÇÃO DOS ESTUDANTES NAS ATIVIDADES PRÁTICAS DE ESTÁGIOS CURRICULARES OBRIGATÓRIOS E INTERNATOS MÉDICOS.}

Com a pandemia da COVID-19 a tríade universitária de ensino, pesquisa e extensão ficou prejudicada e para se manter ativa, atuante e produtiva foram necessárias uma série de reformulações para se adequar à nova realidade. No que diz respeito ao ensino, o uso das tecnologias da informação foram cruciais para a manutenção das aulas de forma remota, dando origem ao Ensino Remoto Emergencial (ERE).

Apesar de necessário para se evitar maiores atrasos nos cronogramas das universidades, o ensino remoto apresenta desafios, principalmente para os cursos da área da saúde, que dependem diretamente do sistema de saúde local para a realização da carga horária prática. Devido a essa incapacidade de suprir a necessidade dos cursos de graduação que as universidades vêm elaborando medidas para que o retorno presencial ocorra da forma mais eficiente e segura possível.

O retorno presencial das atividades de ensino deverá ocorrer de forma gradual, baseando-se em critérios científicos, epidemiológicos; locais, regionais e nacionais; e de infraestrutura das instalações que ocorrerão essas aulas. Mediante o levantamento desses fatores serão elaborados protocolos de biossegurança, para que discentes, docentes, técnicos- 
administrativos em educação (TAE) e outros colaboradores possam retornar suas atividades com segurança.

De acordo com uma análise sistemática de protocolos de biossegurança de instituições de ensino superior, tanto particulares como públicas, foi possível identificar as condições mínimas necessárias para um retorno presencial das atividades de ensino. Essas medidas se baseiam em minimizar o risco de contágio; rastreio de casos suspeitos e dos contatos; isolamento e tratamento dos infectados. Também é recomendação unânime que o momento de reabertura deve ser avaliado de acordo com a situação epidemiológica local e só deve ocorrer em um cenário que indique redução contínua de novos casos de COVID-19 e redução da transmissão comunitária da doença.

As medidas que visam reduzir o risco de contágio, para os cursos da saúde, devem ser divididas naquelas que precisam ser seguidas dentro do ambiente hospitalar e nos demais locais de ensino, guardados os riscos de contaminação em cada local. Sendo que as principais medidas de proteção individual e coletiva são o uso de máscara adequada, higienização frequente das mãos e distanciamento social.

No caso de Jataí, o principal local de prática dos cursos da saúde é o HOSPITAL DAS CLÍNICAS DR. SERAFIM DE CARVALHO - HCSC, que possui um manual do estagiário próprio, nele é possível encontrar todas as informações de prevenção às Infecções Relacionadas à Assistência à Saúde (IRAS), sua divulgação e correto cumprimento deve ser feito a todos os discentes.

Nos outros ambientes relacionados às atividades de ensino são necessários protocolos diferentes que a instituição de ensino deve, por meio de um comitê interno de gerenciamento da COVID-19, criar de acordo com a demanda e a realidade de cada curso, visando ao máximo a proteção da vida.

As medidas de rastreio e isolamento dos infectados devem ser feitas em parceria com a secretaria de saúde local, portanto a instituição de ensino deve ter um canal direto de comunicação com a autoridade sanitária com o intuito de auxiliar o discente a, caso venha a manifestar sintomas da COVID-19, procurar o serviço de referência para o correto aconselhamento quanto ao tratamento sintomático, critérios de gravidade e rastreio de contatos; para barrar a transmissão comunitária do vírus. 


\subsection{PROCEDIMENTOS NECESSÁRIOS DIANTE DE UM CASO SUSPEITO/CONFIRMADO NO ESTABELECIMENTO DE AULAS PRÁTICAS.}

Diante de um caso suspeito ou contato com caso confirmado, ou confirmação de COVID-19 o estudante, servidor ou trabalhador terceirizado que se encontrar com sintomas gripais, deve comunicar imediatamente sua chefia imediata, a coordenação do curso, o orientador ou chefe do laboratório para que as medidas sanitárias sejam realizadas o mais rápido possível a fim de evitar novos casos. Nas unidades e órgãos administrativos ligados à Reitoria é necessário definir qual o setor e quais pessoas serão responsáveis pela recepção da notificação de casos suspeitos, confirmados e contato com alguém com COVID-19, sendo necessário que essas pessoas recebam um treinamento acerca do protocolo adotado e sejam conhecidas por todos os acadêmicos e servidores.

Com a definição do setor e das pessoas responsáveis, é necessário que este monitore a comunidade acadêmica, divulgue amplamente e de forma contínua um questionário para verificação de sintomas a fim de orientar a comunidade acadêmica se deve ou não frequentar a universidade, orientar para que haja a procura de um serviço de saúde da rede pública ou suplementar, assim como, indicar a realização do exame RT-PCR (reação de transcriptase reversa seguida de reação em cadeia da polimerase), indicar quais as medidas que serão adotadas em caso de suspensão de atividades e divulgar os fluxos de prevenção e conduta para aqueles que apresentem sintomas de COVID-19 e contactante.

A conduta para casos suspeitos, ou seja, estudantes, servidores e trabalhadores terceirizados que apresentem sintomas de COVID-19, é de que os ambientes em que o caso suspeito tenha acessado sejam higienizados imediatamente; o estudante/servidor/terceirizado com suspeita de COVID-19 deve ser afastado por 14 dias a partir do início dos sintomas; devem realizar o exame RT-PCR para os casos sintomáticos.

Para os casos em que houver confirmação por meio de teste positivo para COVID-19 (RT-PCR), o estudante/servidor/terceirizado deve ser orientado a quando procurar um serviço de saúde novamente e não frequentar o ambiente acadêmico por 14 dias a partir da data de confirmação; as pessoas que tiveram contato com o caso confirmado (mesma turma ou setor) deverão ter suas atividades presenciais suspensas por 14 dias a partir do momento de confirmação do caso; os contatos também devem ser orientados a procurar um serviço de saúde se apresentarem sintomas; e notificar o responsável/setor o resultado positivo do exame. 
Para o retorno presencial das atividades é necessário que os locais forneçam as condições necessárias para se manter o distanciamento social. Diante disso, é necessário que haja uma mudança no layouts dos ambientes de estudo (salas de aula, laboratórios, sala de reuniões) a fim de que atendam às regras de distanciamento social evitando assim, aglomerações nos espaços, desse modo as salas de aula devem possuir um espaço que permita um distanciamento de no mínimo 1,5m (um metro e meio) entre os alunos/professores devendo, portanto, demarcar as cadeiras que não poderão ser utilizadas, é recomendado também que sejam evitadas atividades em grupo que possam gerar aglomerações, orientar os alunos e professores a não compartilharem seus itens de uso pessoal (livros, canetas, aparelhos eletrônicos e qualquer tipo de material), higienizar as bancadas, computadores e equipamentos antes e após o uso e fazer o uso de máscaras.

No caso dos laboratórios é recomendado que os pesquisadores, professores e alunos façam um escalonamento dos seus horários para diminuir o número de pessoas no ambiente, manter também o distanciamento de 1,5m (um metro e meio) entre as pessoas que estiverem no ambiente, limitar o acesso frequente de visitantes e voluntários que não sejam essenciais para o desenvolvimento das atividades.

\subsection{MEDIDAS DE PROTEÇÃO E PREVENÇÃO INDIVIDUAIS E COLETIVAS AO SARS-COV-2.}

No que tange às medidas de proteção e prevenção para o SARS-CoV-2, incluindo medidas individuais e coletivas foram analisados protocolos de biossegurança de instituições e governos de diversos locais do país, discorrem a respeito, no que se refere à organização de entrada em instituições de ensino definindo como protocolo o uso obrigatório de máscara em todos os ambientes, nos quais a entrada e saída de pessoal se faz controlada por marcação no piso, preferencialmente com portas destinadas para entrada e saída, proporcionando saída com distanciamento de 1,5 metros.

Além disso, realizar a aferição de temperatura por meio de termômetro sem contato, questionando sobre sinais e sintomas da COVID-19, caso estes estejam presentes não permitir a entrada. A disponibilização de álcool 70\% também se faz necessária, assim como de cartazes educativos quanto à doença (SES, 2020).

Em relação às fontes de água potável, bebedouros de pressão e bombas devem ter seu acesso suspenso, e realizar instalação de bebedouros sem contato manual, colocando em suas 
proximidades materiais que possibilitem a limpeza das mãos. Sobre a alimentação, além do preparo adequado dos alimentos para que não haja contaminação, ela deverá ser feita em local adequado seguido, medidas de distanciamento, não sendo permitindo o consumo dentro de sala de aula, em caso de ambientes educacionais que não haja esse espaço, deve-se disponibilizar material para higienização das mãos, manter o distanciamento entre as mesas de 1,5 metros com higienização constante das mesmas, instalação de barreiras físicas caso seja possível.

Além disso, oferecer utensílios para fazer a alimentação que sejam descartáveis ou devidamente acondicionados. Realizar escalonamento para uso desses ambientes (SES, 2020).

No que se refere a ventilação, nos ambientes educacionais devem manter a ventilação natural, se fazendo necessário o uso de ambiente climatizado deve-se mantê-lo constantemente higienizado (SES, 2020).

Os banheiros devem ser higienizados e desinfetados, utilizando-se solução de hipoclorito de sódio ou outra solução que possua a mesma capacidade desinfetante, além de ser respeitado o distanciamento. Deve-se disponibilizar materiais para higienização de mãos e papel higiênico. Conscientizar para que a descarga seja dada com a tampa fechada (SES, 2020).

Quanto aos resíduos sólidos, devem ser descartados em todos os ambientes de preferência através de lixeiras com acionamento da tampa feita por pedal. Atentar-se para o descarte de resíduos sólidos potencialmente contaminados, acondicionando-os em sacos descartáveis (SES, 2020).

Considerando o ambiente de práticas, deve-se seguir o recomendado pelo ambiente de prática que pode variar de acordo com o ambiente no qual o aluno estará inserido. Também deve-se atentar às recomendações emitidas por órgãos e entidades, como o Conselho Nacional de Saúde, o qual emitiu em julho de 2020 no qual discorda de atividades práticas por meios presenciais (CNS, 2020).

\section{CONSIDERAÇÕES FINAIS}

Diante o exposto, é imprescindível perceber que o retorno das aulas práticas presenciais no atual cenário pandêmico depende dos dados epidemiológicos locais em conjunto com os protocolos de biossegurança estabelecidos e aprimorados. A análise de protocolos nacionais e internacionais podem auxiliar os gestores a preparar medidas de biossegurança de acordo com a realidade de cada universidade de forma que todos possam respeitar as normas estabelecidas tanto do corpo docente, quanto do corpo discente para contribuir com as metas sociais e 
educacionais de qualidade proposto pela universidade e sanando as problemáticas emocionais geradas com o fechamento, visando reduzir a evasão universitária e garantir a qualidade de ensino de forma ética. 


\section{REFERÊNCIAS BIBLIOGRÁFICAS}

ATHER, Amber et al. Coronavirus disease 19 (COVID-19): implications for clinical dental care. Journal of endodontics, v. 46, n. 5, p. 584-595, 2020. Disponível em:

https://www.sciencedirect.com/science/article/abs/pii/S009923992030159X. Acesso em: 10 abri. 2021

Boletim Epidemiológico sobre o Coronavírus em Jataí. Secretaria de Saúde de Jataí. [S. l.], 6 abr. 2021. Disponível em: https://www.jatai.go.gov.br/boletim-epidemiologico-sobre-ocoronavirus-em-jatai-57/. Acesso em: 7 abr. 2021.

DA SILVA MOURA, Jackson Felipe et al. COVID-19: A odontologia frente à pandemia. Brazilian Journal of Health Review, v. 3, n. 4, p. 7276-7285 2020. Disponível em: https://www.brazilianjournals.com/index.php/BJHR/article/view/12571. Acesso em: 12 abril, 2021

DINIZ, Michely Correia et al. Crise global coronavírus: Monitoramento e impactos. Cadernos de Prospecção, v. 13, n. 2 COVID-19, p. 359, 2020. Disponível em: https://periodicos.ufba.br/index.php/nit/article/view/35937 . Acesso em 20 abri 2021

IMPRENSA NACIONAL. PORTARIA No 572, DE 1o DE JULHO DE 2020 - DOU Imprensa Nacional. Disponível em: <https://www.in.gov.br/en/web/dou/-/portaria-n-572-de1-de-julho-de-2020-264670332>. Acesso em: 10 abril 2021.

SOARES, Letícia et al. Medidas de prevenção à Covid-19 no retorno às aulas: Protocolos de 13 países. 2020. Disponível em:

https://preprints.scielo.org/index.php/scielo/preprint/download/1082/1590/1671\#: :text=Anali sou $\% 2$ Dse $\% 20$ protocolos $\% 20$ para $\% 20$ reabertura,de $\% 20 \mathrm{~m} \% \mathrm{C} 3 \% \mathrm{~A} 1 \mathrm{scaras} \% 20 \mathrm{e} \% 20 \mathrm{distancia}$ mento\%20socia Acesso em 22 abril 2021.

UFMG (MG). Plano para o retorno presencial de atividades não adaptáveis ao modo remoto. In: UNIVERSIDADE FEDERAL DE MINAS GERAIS (MG). Plano para o retorno presencial de atividades não adaptáveis ao modo remoto. [S. $l],$.21 set. 2020. 27p. Disponível em: http://conselho.saude.gov.br/recomendacoes-cns/1250-recomendacao-n-048de-01-de-julho-de-2020. Acesso em: 14 de abril de 2021

UNICAMP (SP). Orientações para convívio seguro: Orientações sanitárias para o enfrentamento da pandemia. In: Orientações para convívio seguro. [S. l.], 2020. Disponível em:https://www.unicamp.br/unicamp/cartilha-covid-19/orientacoes-sanitarias-para-oenfrentamento-da-pandemia. Acesso em: 11 abr. 2021. 